Supplement of The Cryosphere, 11, 191-215, 2017

http://www.the-cryosphere.net/11/191/2017/

doi:10.5194/tc-11-191-2017-supplement

(c) Author(s) 2017. CC Attribution 3.0 License.

(c) (i)

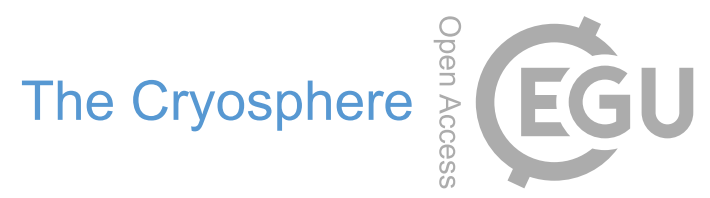

Supplement of

\title{
Diagnosing the decline in climatic mass balance of glaciers in Svalbard over 1957-2014
}

Torbjørn Ims Østby et al.

Correspondence to: Torbjørn Ims Østby (torbjorn.ostby@geo.uio.no)

The copyright of individual parts of the supplement might differ from the CC-BY 3.0 licence. 


\section{S1 Meteorological measurements at Svalbard Airport}

The 117 year long homogenized air temperature record after ? from Svalbard airport is shown in Figure S1, Over the period all seasons has a positive trend with the largest warming during winter and lowest warming during summer. Summer temperature trend is not easily seen in Figure S1 Since 1976 daily meteorological measurements allow for estimating a common measure of glacier melt, yearly cumulative positive degree days ( $\Sigma \mathrm{PDD}$ ), which show a markedly increase over the last 40 years (Fig. S2).

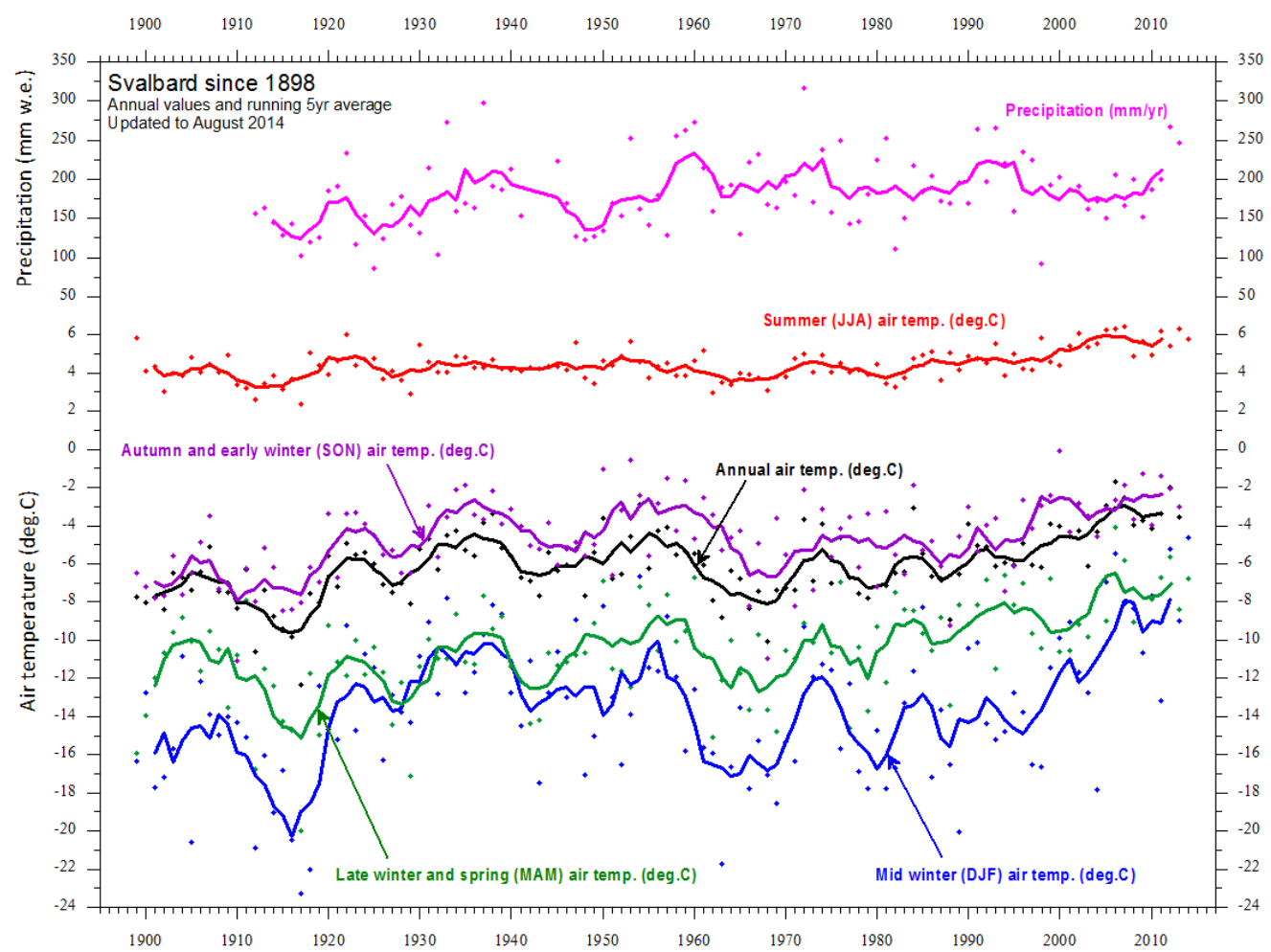

Figure S1. Air temperatures and precipitation at Svalbard Airport 1898-2014 from climate4you.com with data from eklima.no

\section{S2 Glacier masks}

Figure S3 shows the glacier coverage at three epochs, 1930-60s, 1990s, and 2000s, (?). Regional glacier area for the applied temporally evolving glacier mask, which was is derived by interpolation of the ? inventory, is shown in Figure $\$$ F For some locations like Kvitøya, glacier coverage is only available for the last epoch and the glacier area is constant for the entire period. This approach assume linear glacier retreat or advance between the epochs and no changes are assumed 


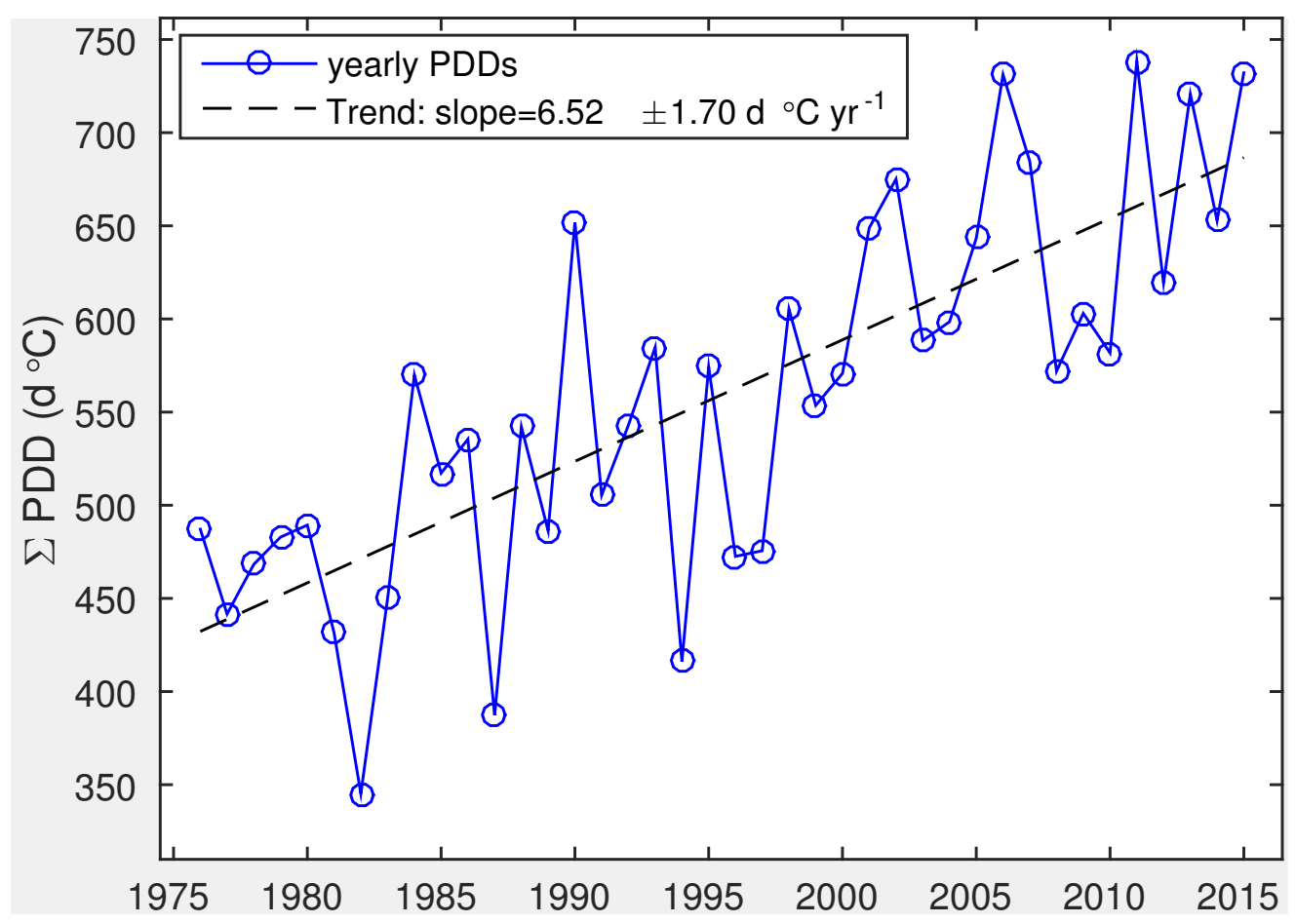

Figure S2. Accumulated positive degree days from Svalbard airport 1976-2015. Data from eklima.no

after the 2000s epoch. Representation of glacier tongue retreats are somewhat unrealistic, since they

disintegrate rather than displaying a frontal retreat.

\section{S3 MODIS}

Figure S5 shows MODIS-derived average over 2003-13 for: minimum summer (lower 5th percent) albedo and mean annual clear-sky skin surface temperatures.

\section{S4 Calibration}

Table S1 list relevant parameters employed in the model and how the respective values are determined. Only four parameters were determined during the calibration. Expert judgment are values based on one or more of the following: 1) from a pre-calibration step with many more than the 4 parameters, to aid the parameter choice in the next calibration exercise; 2 ) from fitting to observations, where direct comparison where possible; 3 ) from a mixture of values found in the literature. 


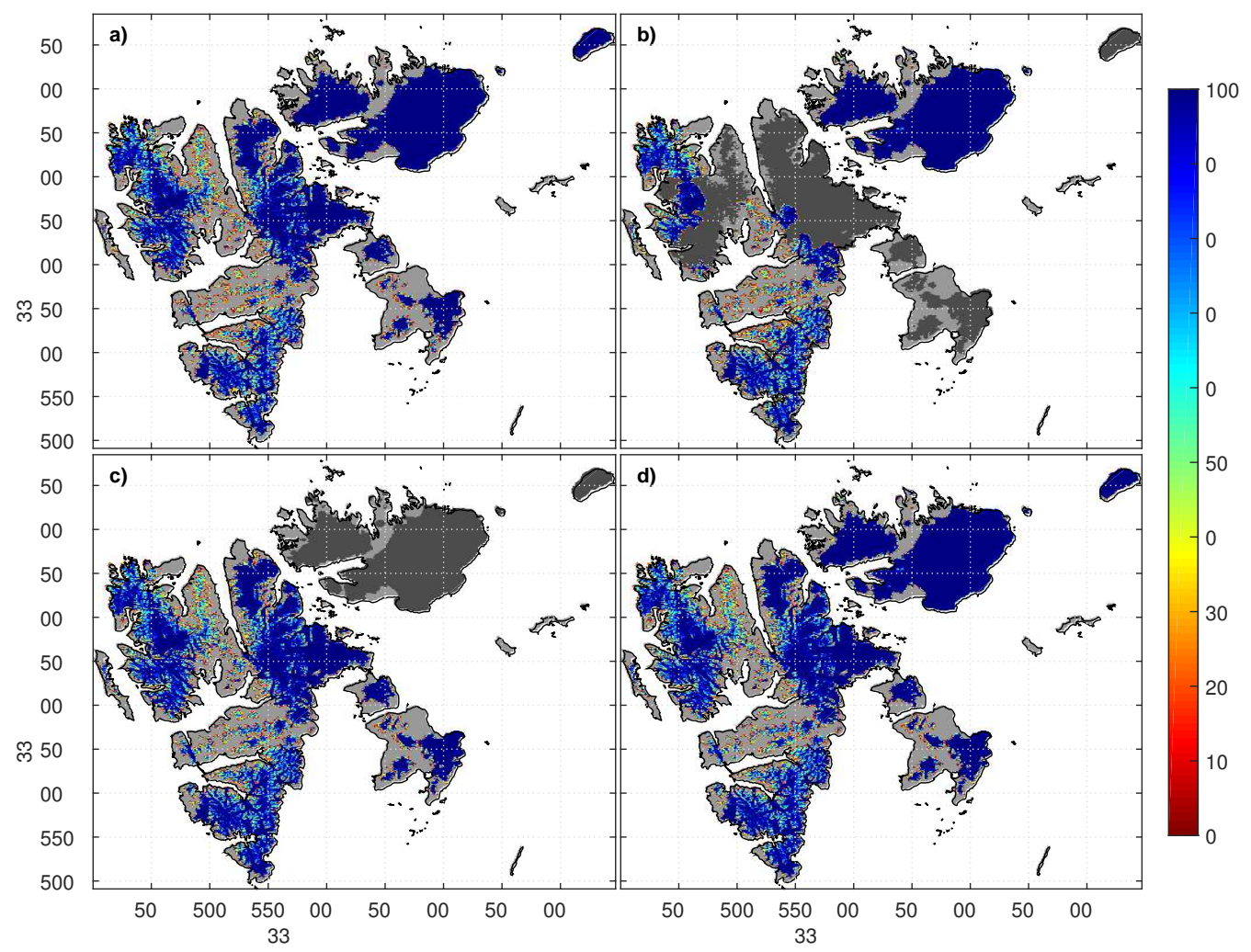

Figure S3. Fractional glacier cover (\%) on 1000m DEM: a) 2000s, b) 1990s, c) 1930s/60s and d) reference mask

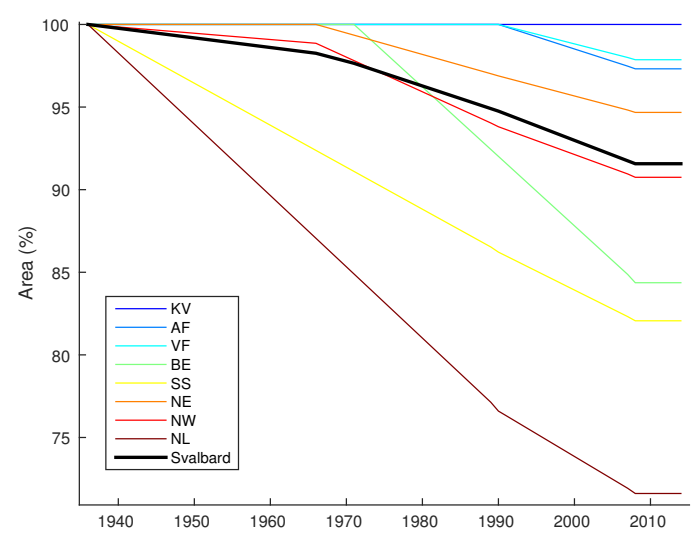

Figure S4. Glacier area evolution for Svalbard and it's regions in percent from the first data acquisition in 1936 and onwards constructed from the multi-temporal glacier inventory (?). 

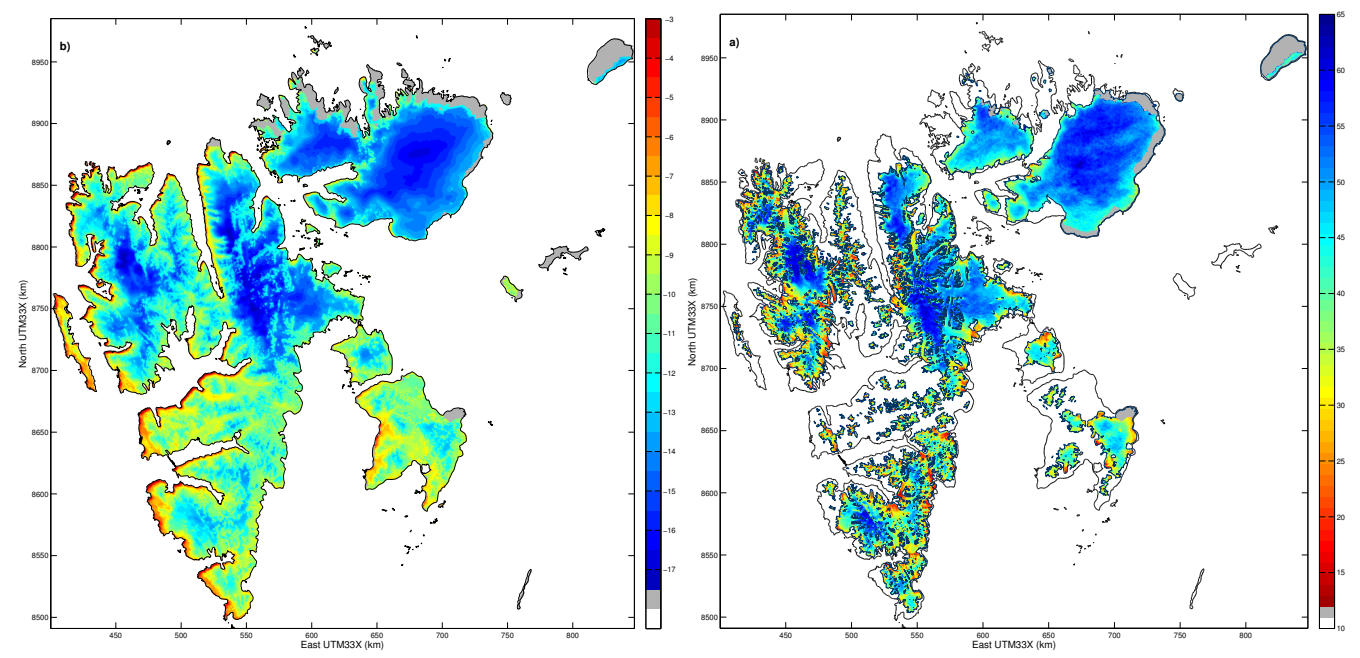

Figure S5. a) Mean annual clear-sky skin surface temperatures from MODIS over 2003-2013. b) Minimum (lower 5th percentile) summer albedo averaged over 2003-2013 derived from MODIS. Missing data (in gray) are caused by erroneous landmask in MODIS.

\section{S5 Regional Refreezing and Thermal regime}

Figure \$6 and [57 shows yearly amount of refreezing and $15 \mathrm{~m}$ temperatures with altitude resolved regionally. All regions show nearly the same response regarding thermal regime for the period 19572014, thus occurring at different elevation. The main features are: 1) warming of the cold ice in the ablation area; 2) cooling of the the area around ELA, which climb increase as firn area shrinks with the increasingly negative $B_{\text {clim }}$; 3) warming of the cold firn area which existed until 1975, when nearly all firn became temperate. 
Table S1. Overview on parameters and parameterization employed in the model and their origin.

\begin{tabular}{|c|c|c|c|c|}
\hline Process & Parameter & Symbol & Value & Source \\
\hline \multirow{3}{*}{ Turbulent fluxes } & \multirow{2}{*}{ Roughness lengths of momentum } & $z o_{i c e}(\mathrm{~mm})$ & 0.18 & Calibration \\
\hline & & $z o_{\text {snow }}(\mathrm{mm})$ & 0.06 & Calibration \\
\hline & Roughness length heat/moist & $z o_{T / q}(\mathrm{~mm})$ & see & $?$ \\
\hline \multirow{12}{*}{ Albedo } & Ice & $\alpha_{\text {ice }}(-)$ & 0.30 & Calibration \\
\hline & Firn/ min snow & $\alpha_{f i r n}(-)$ & 0.62 & Calibration \\
\hline & New snow & $\alpha_{\text {snow }}(-)$ & 0.85 & Expert judgment \\
\hline & Slush & $\alpha_{\text {slush }}(-)$ & 0.55 & Expert judgment \\
\hline & Superimposed ice & $\alpha_{S I}(-)$ & 0.67 & Expert judgment \\
\hline & Water & $\alpha_{\text {water }}(-)$ & 0.15 & $?$ \\
\hline & Slush & $\alpha_{\text {slush }}(-)$ & $\mathrm{xx}$ & Expert judgment \\
\hline & Aging wet snow & $t_{w e t}^{*}(\mathrm{~d})$ & 5 & Expert judgment \\
\hline & Aging dry snow $0^{\circ} \mathrm{C}$ & $t_{d r y\left(0^{\circ} \mathrm{C}\right)}^{*}(\mathrm{~d})$ & 15 & Expert judgment \\
\hline & Aging cold snow $-10^{\circ} \mathrm{C}$ & $t_{d r y\left(-10^{\circ} \mathrm{C}\right)}^{*}(\mathrm{~d})$ & 100 & Expert judgment \\
\hline & Depth scale snow & $d^{*}(\mathrm{~cm})$ & 3 & $?$ \\
\hline & Depth scale water & $w^{*}(\mathrm{~cm})$ & 30 & $?$ \\
\hline Long wave radiation & Emissivity & $\epsilon(-)$ & 0.99 & $?$ \\
\hline Heat conductivity & Ice conductivity & $a\left(\mathrm{~W} \mathrm{~m}^{-1} \mathrm{~K}^{-1}\right)$ & 2.3 & Expert judgment \\
\hline$(?)$ & Exponent & $b(-)$ & 2.35 & Expert judgment \\
\hline Runoff & timescales & $\tau_{\text {steep }}, \tau_{1^{\circ}}, \tau_{0^{\circ}}$, Factor & see & $?$ \\
\hline Precipitation & Rain/snow threshold & $T_{\text {rain } / \text { snow }}\left({ }^{\circ} \mathrm{C}\right)$ & 1.5 & Expert judgment \\
\hline Fresh snow density & Density & $\rho_{f s n}\left(\mathrm{~kg} \mathrm{~m}^{-3}\right)$ & 300 & Expert Judgment \\
\hline Densification & & & & $?$ \\
\hline Irreducible water content & & & & $?$ \\
\hline
\end{tabular}




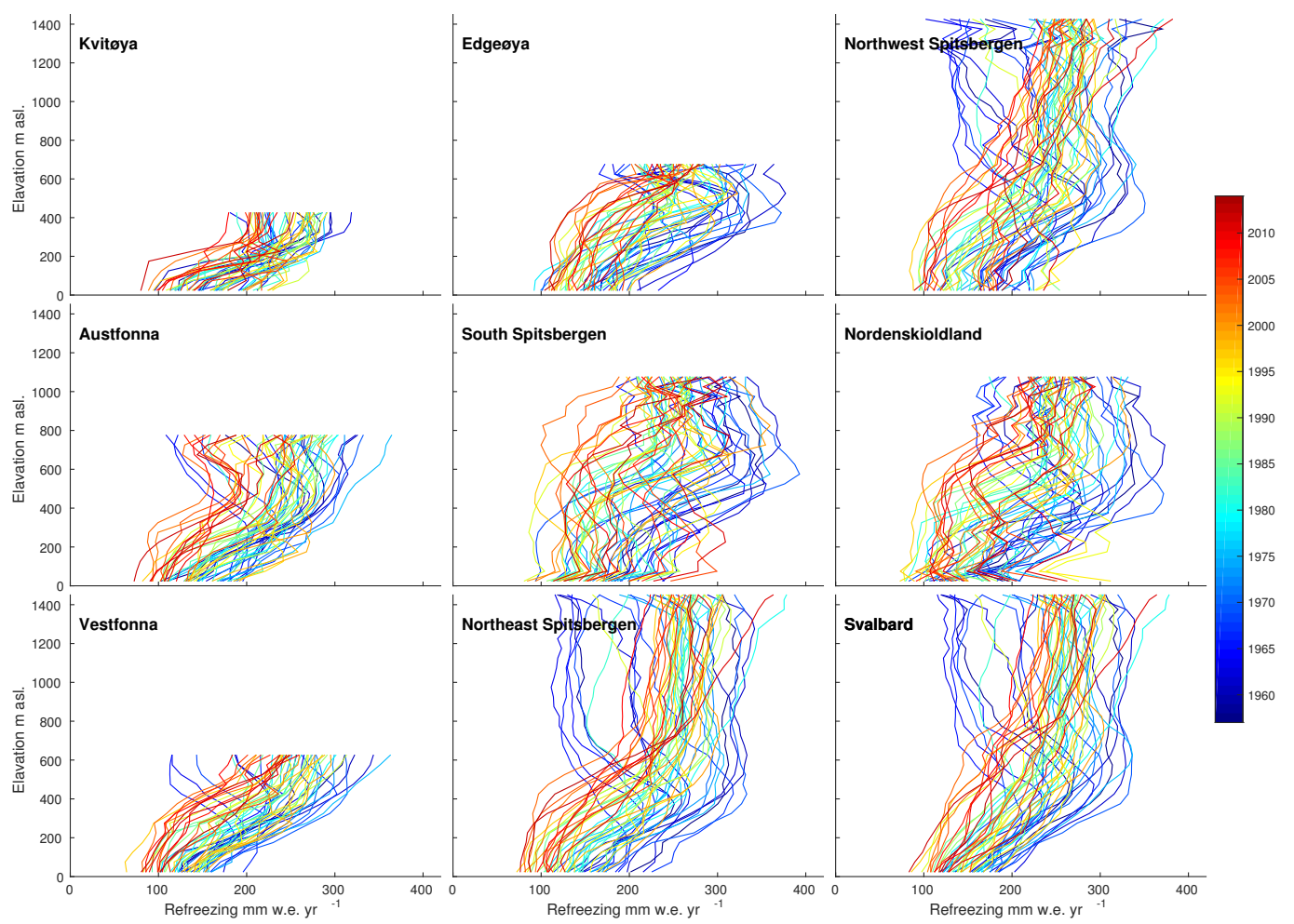

Figure S6. Refreezing averaged over $50 \mathrm{~m}$ altitude intervals for Svalbard and for 8 regions, for each year from 1957 (blue) to 2014 (red). 


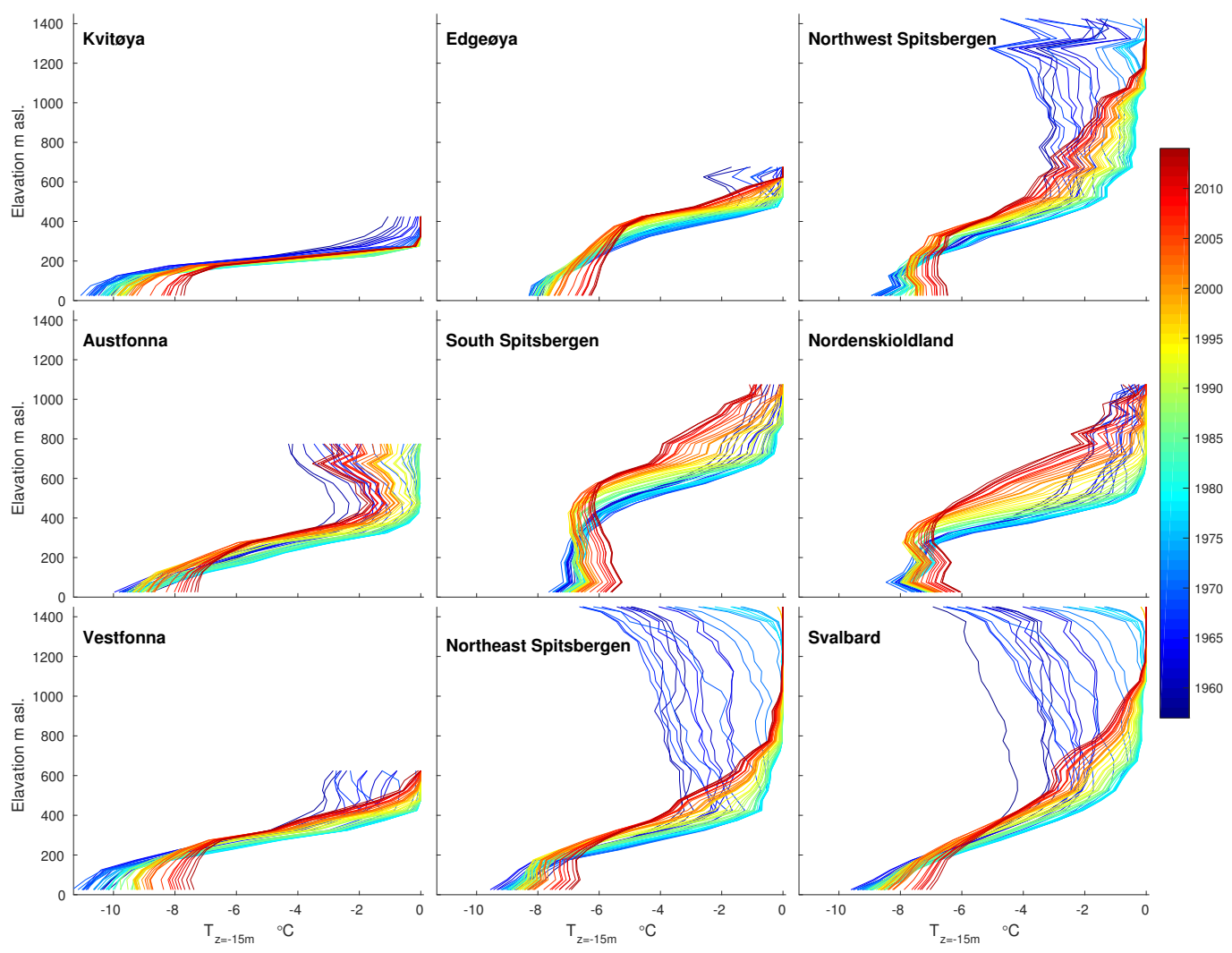

Figure S7. Subsurface temperatures at $15 \mathrm{~m}$ depth averaged over $50 \mathrm{~m}$ altitude intervals for Svalbard and for 8 regions, for each year from 1957 (blue) to 2014 (red). 